\title{
Autoinflammatory Diseases in Childhood
}

\author{
Mehmet Yıldız, Fatih Haşlak, Amra Adrovic, Kenan Barut, Özgür Kasapçopur
}

Department of Pediatric Rheumatology, İstanbul University-Cerrahpaşa Cerrahpaşa School of Medicine, İstanbul, Turkey

Autoinflammatory diseases are characterized by recurrent fevers and clinical findings of impaired natural immunity and can involve various organ systems. The concept of autoinflammatory disease emerged after the definition of familial Mediterranean fever and tumor necrosis factor receptor-associated periodic syndrome. This new disease group was considered to differ from the standard concept of autoimmune diseases, which is relatively better known in terms of basic features, such as defects in innate immunity and the absence of antibodies. A better understanding has been achieved regarding the genetic and pathogenetic mechanisms of this relatively new disease group over the past 20 years since they were first diagnosed, which have led to some changes in the concept of autoinflammatory diseases.
The recent definition classifies autoinflammatory disease to be a wide range of diseases with different clinical features, mainly accompanied by changes in innate immune and rarely in humoral immunity. The spectrum of autoinflammatory diseases is rapidly expanding owing to recent developments in molecular sciences and genetics. This review article discusses the clinical features, classification criteria, treatment options, and long-term prognosis of periodic fever, aphthous stomatitis, pharyngitis, adenitis syndrome, and other common autoinflammatory diseases in the light of current literature.

Keywords: Autoinflammatory diseases, childhood, classification, treatment, prognosis
Autoinflammatory diseases are a group of diseases that occur because of the dysfunction or dysregulation of innate immunity and can cause serious morbidity and mortality by affecting multiple organ systems. This new group differs from the standard concept of autoimmune diseases, which is relatively better known in terms of basic features, such as defects in innate immunity and the absence of antibodies circulating in the bloodstream. The concept of autoinflammatory disease emerged after the definition of familial Mediterranean fever (FMF). Notably, the spectrum of autoinflammatory diseases is rapidly expanding owing to recent developments in molecular sciences and genetics.

\section{Definition and concept of autoinflammation}

Until date, several definitions have been proposed to describe this group of rare diseases (1). The term "autoinflammatory diseases" was first described by the National Institutes of Health as systemic diseases characterized by non-provoking attacks, without hightitrating antibodies and antigen-specific $\mathrm{T}$ lymphocytes (2). In 2010, Kastner et al. (3) defined autoinflammatory disease as "clinical disorders marked by abnormally increased inflammation, mediated predominantly by cells and molecules of the innate immune system, with a significant host predisposition". In 2017, Wekell et al. (4) modified this definition as "autoinflammatory diseases are immunological diseases defined by abnormally increased inflammation, driven by dysregulation of molecules and cells of the innate immune system with a host predisposition as necessary and sufficient criteria, frequently associated with activation of the adaptive immune system and potentially with immune dysfunctions, such as susceptibility to infections, autoimmunity or uncontrolled hyperinflammation." Finally, in 2018, the Pediatric Rheumatology International Trials Organization (PRINTO) defined autoinflammatory diseases as "clinical disorders caused by defect(s) or dysregulation of the innate immune system, characterized by recurrent or continuous inflammation (elevated acute phase reactants) and the lack of a primary pathogenic role for the adaptive immune system (autoreactive T-cells or autoantibody production)" (1).

The changes in the definition of the disease reflect the expansion of the spectrum and the classification of new diseases under this group. The recent definition of autoinflammatory disease classifies it as a wide range of diseases exhibiting different clinical features, mainly accompanied by changes in innate immune and rarely in humoral immunity. Diseases classified presently under the group of autoinflammatory diseases are summarized in Table 1. This review article discusses the clinical features, classification criteria, treatment options, and long-term prognosis of periodic fever, aphthous stomatitis, pharyngitis, adenitis (PFAPA) syndrome, and other common autoinflammatory diseases.

\footnotetext{
Address for Correspondence: Özgür Kasapçopur, Department of Pediatric Rheumatology, İstanbul University-Cerrahpaşa Cerrahpaşa School of Medicine, İstanbul, Turkey e-mail: ozgurkasapcopur@hotmail.com_ ORCID: orcid.org/0000-0002-1125-7720

Received: 12 April $2020 \quad$ Accepted: 26 April 2020 • DOI: 10.4274/balkanmedj.galenos. 2020.2020.4.82

Available at www.balkanmedicaljournal.org

Cite this article as:

Yıldız M, Haşlak F, Adrovic A, Barut K, Kasapçopur Ö. Autoinflammatory Diseases in Childhood. Balkan Med J 2020;37:236-46

${ }^{\circ}$ Copyright 2020 by Trakya University Faculty of Medicine / The Balkan Medical Journal published by Galenos Publishing House.
} 


\section{Diagnostic approach for patients with suspected autoinflammatory disease}

Fever is one of the most common reasons for hospital admission during childhood, with infections being the leading cause of fever in children. The initial step in the evaluation of a child with fever is the definition of fever and its characteristics. It should be kept in mind that parents can subjectively exaggerate the symptoms, and if parents complain regarding recurrent fevers, a fever diary that is filled objectively should be requested. Fever diary is a useful tool in confirming the fever and identifying fever patterns like periodic, recurrent, or prolonged.

TABLE 1. Classification of the autoinflammatory diseases based on the pathogenesis

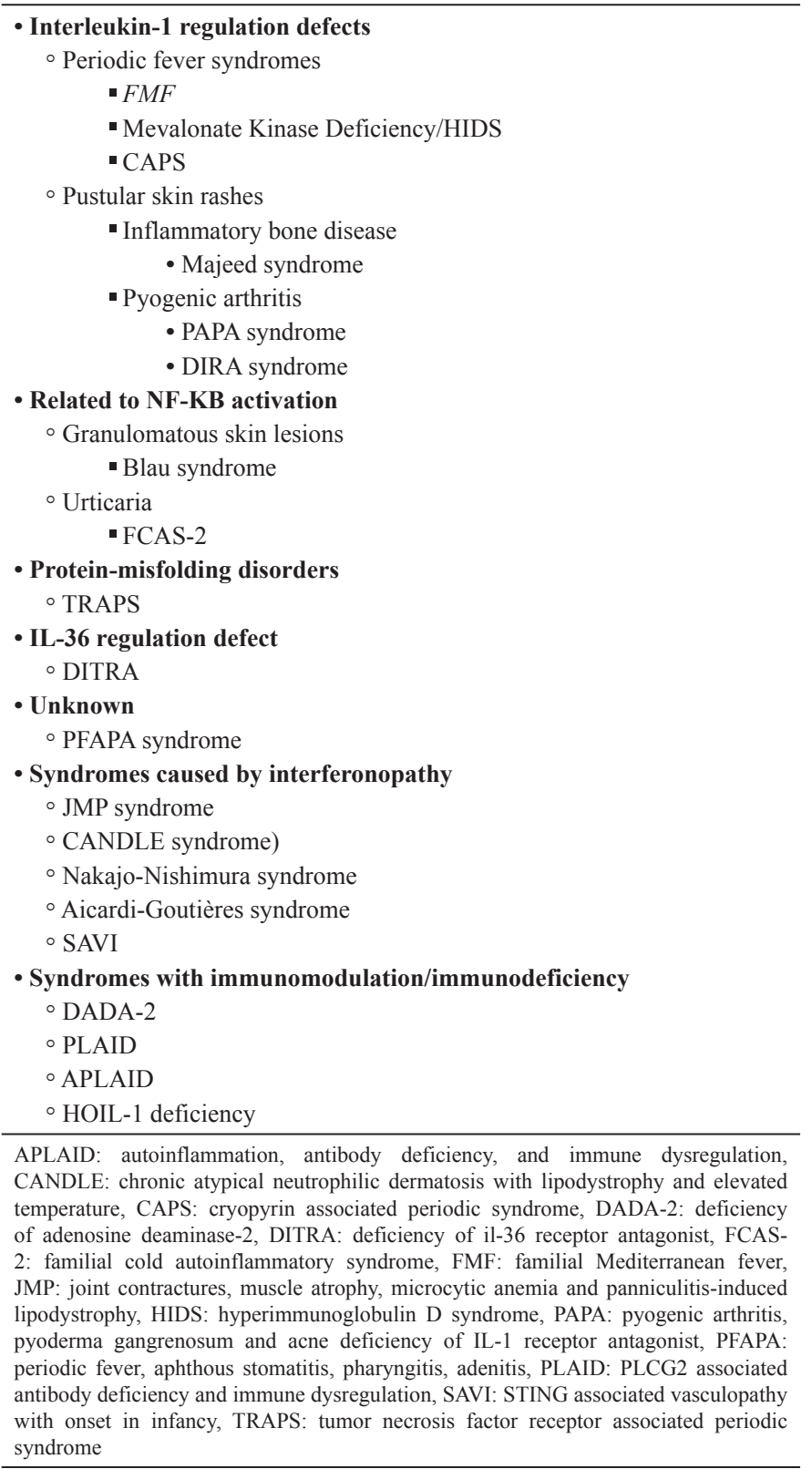

In the case of recurrent or periodic fever, a detailed medical history of the patient and family should be obtained, and cautious physical examination should be performed. Nonetheless, considering the rarity of autoinflammatory diseases, other possible reasons for periodic or recurrent fever should be considered, such as recurrent infections, malignancies, immunodeficiencies like cyclic neutropenia. Moreover, fever can be a sign of Munchausen syndrome by proxy, and accordingly, physicians should be vigilant regarding every child with recurrent fever. While developmental delay, growth restriction, and history of hospitalization for severe infections primarily suggest possible immunodeficiency, night sweats, night pains, weight loss, generalized lymphadenopathy, or hepatosplenomegaly may indicate malignancies. On the other hand, indications suggestive of autoinflammatory diseases are normal growth and development patterns, asymptomatic between episodes, positive family history, and history of similar episodes. A diagnostic approach algorithm is presented in Figure 1.

\section{Periodic fever, aphthous stomatitis, pharyngitis, adenitis syndrome}

PFAPA syndrome is one of the most common periodic fever syndromes observed during childhood (5). However, the etiology and genetic basis of this unique disease is still unclear (6). Literature reveals a common misuse of nomenclature of diseases with recurrent or periodic fever. Most authors classify the autoinflammatory diseases under an umbrella of periodic fever, although most of these diseases have recurrent fever rather than periodic fever. The most crucial exception is PFAPA syndrome. The episodes of PFAPA syndrome typically have a perfect periodicity that allows families to predict the occurrence of the next episode. The genetic background of this syndrome is still a critical topic of discussion and research. Although the literature reports a high rate of positive family history in patients with PFAPA syndrome suggestive of possible genetic transmission, Di Gioia et al. (7) could not determine a causative gene by conducting whole-exome sequencing studies, and they suggested that PFAPA is related to the oligogenic or complex inheritance of various genetic and nongenetic factors (8-10). The relationship between PFAPA syndrome and other autoinflammatory disease genes is another topic of interest. Patients with underlying pathogenic variants of other autoinflammatory diseases tend to have an atypical presentation of PFAPA syndrome $(11,12)$. Some studies in the literature have reported an increased frequency of Mediterranean Fever (MEFV) gene mutations in patients with PFAPA syndrome. The frequency of the $M E F V$ mutations in patients with PFAPA syndrome is reported to be $8 \%-66 \%(8,12-15)$. It has been reported that patients with PFAPA having $M E F V$ mutations have shorter episodes, longer inter-episodic intervals, and lower corticosteroid dose requirement for the disease attacks cessation (16-18). In contrast, Pehlivan et al. (15) observed that patients with PFAPA syndrome having underlying $M E F V$ mutations have a severe clinical course.

Although sporadic adult cases have been reported, the disease typically occurs in children younger than 5 years of age (5). Periodic fever is the most prominent finding of the disease. The fever is typically accompanied with aphthous stomatitis, 


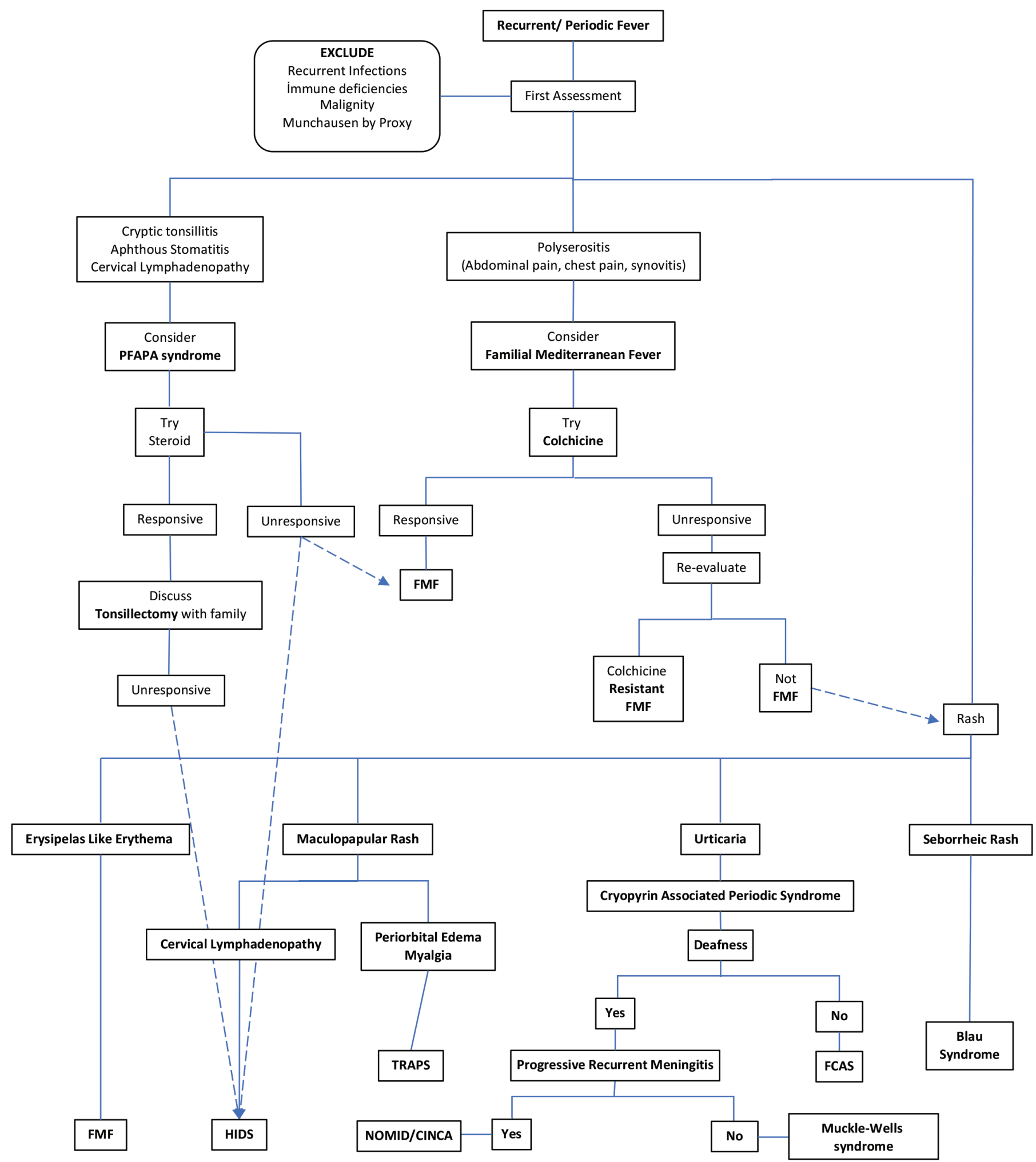

FIG. 1. Diagnostic approach algorithm in children with recurrent fever.

CINCA: chronic infantile neurological, cutaneous, and articular syndrome, FMF: familial Mediterranean fever HIDS: hyperimmunoglobulin D, NOMID: neonatal-onset multisystem inflammatory disease, PFAPA: periodic fever, aphthous stomatitis, pharyngitis, adenitis syndrome, TRAPS: tumor necrosis factor receptor-associated periodic syndrome 
pharyngitis, and adenitis. The episodes often end within a week and recur every 2-8 weeks (11). The early episodes typically exhibit perfect periodicity, enabling the family to predict the next occurrence. The periodicity of the episodes typically disappears during the disease course, the attack-free intervals become longer, and finally, the episodes cease 3-5 years after the onset $(5,11)$. Notably, no developmental and growth delays occur in children with PFAPA syndrome. Fever in PFAPA syndrome can be as high as $39-40^{\circ} \mathrm{C}$, typically unresponsive to antipyretics. Despite the high fever, children do not appear ill, and this is a useful clue for diagnosing PFAPA. Exudative tonsillopharyngitis or cryptic tonsillitis is another crucial finding of the disease and often occurs along with aphthous stomatitis. The oral findings of the disease typically disappear rapidly within a day after a single dose of steroids. In addition, cervical lymphadenitis is commonly observed during the disease attacks, and this is most often bilateral and tender (5). Because enlarged cervical lymphadenitis is one of the clinical findings of hyperimmunoglobulin D syndrome (HIDS)-another autoinflammatory disease-it is sometimes misdiagnosed as PFAPA syndrome. Therefore, HIDS should be considered in patients with PFAPA unresponsive to tonsillectomy. Nevertheless, abdominal pain, arthralgia, myalgia, and headache are rarely reported during disease episodes (11).

PFAPA is diagnosed based on clinical findings. The most commonly used diagnostic criteria for PFAPA syndrome are modified Marshall's criteria (19). According to these criteria, diagnosis is based on regularly recurring fever with an early onset ( $<5$ years), absence of cyclic neutropenia, being completely asymptomatic between episodes, normal development and growth, and at least one of the following three criteria: aphthous stomatitis, cervical lymphadenitis, and pharyngitis (19). In 2018, Vanoni et al. (20) proposed a new set of classification criteria for PFAPA syndrome. The sensitivity and specificity of this new set of criteria were reported as $89.7 \%$ and $69.5 \%$ by Adrovic et al. (21), and they suggested that these newly proposed criteria are insufficient in distinguishing FMF from PFAPA syndrome, especially in regions endemic for FMF. Eurofever/PRINTO suggested new sets of classification criteria for PFAPA syndrome with a sensitivity of $97 \%$ and specificity of $93 \%$ (22). The diagnostic or classification criteria for PFAPA are presented in Table 2.
Although PFAPA syndrome is a benign condition and typically resolves spontaneously after 5 years of age, the recurrent episodes can exhaust the families and children, forcing them to seek treatment for the disease. Nonetheless, only few drugs have been proven effective in treating PFAPA syndrome. Notably, colchicine, cimetidine, vitamin D, anti-interleukin 1 (IL-1) therapy, and tonsillectomy are the recommended treatment options for the disease (23). Although steroids have been noted to be highly effective in terminating the episodes, it is shown that using steroids shortens the intervals between fever attacks (23). Considering the possible side effects of steroids, it should not be used routinely in all the episodes. Notably, being responsive to steroids can be accepted as a clue for diagnosis of PFAPA syndrome and trying the steroid treatment in patients with PFAPA syndrome suspicion may be logical. Colchicine has been shown to be effective in reducing the frequency of the episodes, with a more prominent effect in patients with $M E F V$ mutation in some studies $(11,14,15)$. Therefore, colchicine should be considered before performing tonsillectomy in a certain percent of PFAPA patients, especially those from regions endemic for FMF. Tonsillectomy is another treatment option for PFAPA syndrome. The efficacy of tonsillectomy is reported to be $92 \%$ in the literature (11). Because PFAPA syndrome is a benign condition, tonsillectomy should be discussed in detail with the family during decision-making.

\section{Familial Mediterranean Fever}

FMF is the most common hereditary autoinflammatory disease with an autosomal recessive inheritance pattern, characterized by recurrent fever attacks and polyserositis $(24,25)$. The disease occurs most frequently in communities living in the Mediterranean basin, with the highest prevalence reported among Sephardic Jews, Armenians, Turks, and Arabs (26).

$M E F V$ encoding pyrin protein is the causative gene of the disease (27). Although the classical inheritance pattern of the disease is autosomal recessive, a vertical inheritance pattern resembling pseudo-dominant inheritance has also been reported in some families from regions with a high carrier frequency of MEFV variants (28). The carrier frequency rate was reported to be approximately 1/6 among Sephardic Jewish, 1/5 among Armenian, and 1/8-1/5 among Turkish people. Thus far, 374 variants of this gene have been identified (https:// infevers.umai-montpellier.fr/web/) (29). The most common disease-

TABLE 2. The proposed classification criteria for periodic fever, aphthous stomatitis, pharyngitis, adenitis syndrome

\begin{tabular}{|c|c|c|}
\hline Modified Marshall's criteria (19) & Criteria by Vanoni et al. (20) & Eurofever/PRINTO criteria (22) \\
\hline $\begin{array}{l}\text { - Recurring fever with regular intervals (onset }<5 \\
\text { years of age) } \\
\text { - Constitutional symptoms with one of the } \\
\text { following three: } \\
{ }^{\circ} \text { Aphthous stomatitis } \\
{ }^{\circ} \text { Cervical lymphadenitis } \\
{ }^{\circ} \text { Pharyngitis } \\
\text { - Absence of cyclic neutropenia } \\
\text { - Asymptomatic intervals between episodes } \\
\text { - Absence of developmental delay or growth } \\
\text { restriction }\end{array}$ & $\begin{array}{l}\text { - Periodic fever for at least } 6 \text { months: } \\
{ }^{\circ} \text { Daily fever of } 38.5^{\circ} \mathrm{C} \text { for } 2-7 \text { days } \\
{ }^{\circ} \text { At least five fever attacks with regular intervals } \\
\text { (maximum of } 2 \text { months) } \\
\text { - Pharyngitis, cervical adenitis, oral aphthae: at least one in } \\
\text { every episode and at least two in most episodes } \\
\text { - Exclusion of other causes of recurrent fever } \\
\text { - Exclusion of infections, immunodeficiency, cyclic } \\
\text { neutrophilia } \\
\text { - Disease onset }<6 \text { years } \\
\text { - Being asymptomatic between episodes } \\
\text { - Normal growth }\end{array}$ & $\begin{array}{l}\text { At least seven of the following eight: } \\
\text { Presence of: } \\
\text { - Pharyngotonsillitis } \\
\text { - 3-6 days long episodes } \\
\text { - Cervical lymphadenitis } \\
\text { - Periodicity } \\
\text { Absence of: } \\
\text { - Diarrhea } \\
\text { - Chest pain } \\
\text { - Skin rash } \\
\text { - Arthritis }\end{array}$ \\
\hline
\end{tabular}


causing mutations are M694V, V726A, M694I, and M680I, located in the exon 10 (30). It is well-known that, unlike other diseases with autosomal recessive inheritance, the classical FMF phenotype can be noted in patients carrying only one MEFV mutation and even no MEFV mutations. Therefore, the role of gene analysis in diagnosis is limited, and it is typically used for predicting the prognosis or course of the disease. Notably, patients with homozygous M694V mutations have been reported to have severe disease and an increased risk of amyloidosis (24).

In most patients, the disease occurs during childhood, with the first disease episode typically occurring during the first 10 years of life (31). The mean age of the disease onset was reported to be 3-9 years (24). It is characterized by fever and abdominal pain episodes resembling an acute abdomen. Contrary to the nomenclature that named these diseases as periodic fever syndromes, it is more accurate to define the disease episodes as recurrent instead of periodic (24). Nonetheless, the episodes typically resolve within $72 \mathrm{~h}$. Although an apparent prodromal period has been reported in adult patients, episodes in children often start suddenly without any prodromal findings, as well as end spontaneously $(25,32)$. This difference in symptom presentation could be because of the inability of young children to express their pre-attack symptoms, and the prodromal period could be an overlooked finding of the disease in children (25). Despite various types of disease episodes, the most common clinical phenotype is the coexistence of fever, abdominal pain, and articular findings.

Notably, fever is one of the most commonly reported findings of the disease (33). Even though it can be the only finding, it is often accompanied by at least one of the other findings. Another crucial finding of the disease is severe abdominal pain resembling an acute abdomen (34). Because abdominal pain is very severe, most patients are misdiagnosed as acute appendicitis during attacks, and an appendectomy is performed before the FMF is diagnosed (34). The reason for the abdominal pain is aseptic serositis, which is also responsible for chest pain that can be caused by pericarditis or pleuritis (34). Another common finding of the disease is articular involvement, and it could be the only presentation of the disease. The typical articular involvement of the disease causes non-erosive, non-migratory mono- or oligoarthritis of lower extremities that resolves spontaneously within a week. Chronic arthritis has been reported in $2 \%-5 \%$ of patients (24). An erythematous rash can be observed over the involved joint, and this unique sign is termed as "red arthritis" (24). In addition, seronegative sacroiliitis has been reported in patients with FMF $(33,35)$. The most common skin finding in FMF is erysipelaslike erythema that is typically noted on the dorsum of the foot (24) (Figure 2A). In addition, orchitis and aseptic meningitis have been reported in FMF (24). Myalgia is another crucial symptom frequently noted in patients with FMF (24). Apart from being the presenting symptom of FMF, myalgia can also be a sign of protracted febrile myalgia. It is a rare vasculitic manifestation of the disease, which is characterized by symmetric severe muscle pain, tenderness, elevated acute phase reactants, normal muscle enzyme levels, excellent response to steroids, and absence of articular findings (36).

Apart from protracted febrile myalgia, the frequency of other vasculitides, such as Henoch Schoenlein purpura, polyarthritis nodosa, Behcet's syndrome, and even some other inflammatory diseases like juvenile idiopathic arthritis, psoriasis, and inflammatory bowel diseases are observed to be increased in patients with FMF $(37,38)$.

FMF is diagnosed based on clinical findings. Mutation testing is not required in all suspected patients. As mentioned earlier, knowing the genotypes of $M E F V$ mutations provides an insight into the course and prognosis of the disease. Because FMF represents the oldest autoinflammatory disease, several classifications and diagnostic criteria have been suggested. The most commonly known and used ones are Tel Hashomer and Yalcinkaya-Ozen criteria $(39,40)$. According to Yalcinkaya-Ozen criteria, at least two of the following five criteria are required for diagnosis: fever, abdominal pain, chest pain, oligoarthritis, and positive family history of FMF. Moreover, these clinical symptoms should be observed at least three times and should last between 6-72 $\mathrm{h}$ to be considered as a criterion (39). Recently, two new sets of classification criteria (combined and only clinical) were proposed by PRINTO (Table 3) (22). The main difference between the new

TABLE 3. Eurofever/Pediatric Rheumatology International Trials Organization classification criteria for Familial Mediterranean Fever (22)

\begin{tabular}{|c|c|}
\hline Classification criteria & Clinical classification criteria \\
\hline $\begin{array}{l}\text { Presence of pathogenic (or likely pathogenic) MEFV variants (homozygous or in trans } \\
\text { (or biallelic) compound heterozygous) and at least one of the following: } \\
\text { - } 1 \text {-3 days long attacks } \\
\text { - Arthritis } \\
\text { - Chest pain } \\
\text { - Abdominal pain } \\
\text { OR } \\
\text { Presence of in trans compound heterozygous for one pathogenic MEFV variants and } \\
\text { one variant of uncertain significance (VUS) or biallelic } V U S \text { or heterozygous for one } \\
\text { pathogenic MEFV variant and at least two of the following: } \\
\text { - } 1 \text {-3 days long attacks } \\
\text { - Arthritis } \\
\text { - Chest pain } \\
\text { - Abdominal pain }\end{array}$ & $\begin{array}{l}\text { At least six of the following nine: } \\
\text { Presence of: } \\
\text { - Eastern Mediterranean Ethnicity } \\
\text { - } 1-3 \text { days long attacks } \\
\text { - Chest pain } \\
\text { - Abdominal pain } \\
\text { - Arthritis } \\
\text { Absence of: } \\
\text { - Aphthous stomatitis } \\
\text { - Urticaria } \\
\text { - Maculopapular rash } \\
\text { - Painful lymphadenopathy }\end{array}$ \\
\hline
\end{tabular}


criteria and the earlier one is the inclusion of patient genotype. Sag et al. (41) reported that this new set of criteria is more sensitive (96\%) and less specific (73.1\%) than Tel Hashomer and Yalcinkaya-Ozen criteria.

The primary aim of FMF treatment is to prevent amyloidosisthe most critical complication of the disease. Notably, colchicine is the mainstay of FMF treatment. Colchicine was first shown to be effective in FMF by Ozkan et al. (42) and then Goldfinger (43). The recommended dose is $0.5 \mathrm{mg}$ (or $1 \mathrm{mg}$ ) for children under 5 years of age, $0.5-1 \mathrm{mg}$ for children between 5 and 10 years of age, and 1-1.5 mg for children older than 10 years of age. The maximum dose of colchicine for children is $2 \mathrm{mg}$ per day. In the case of uncontrolled episodes with $2 \mathrm{mg}$ colchicine per day, drug compliance should be assessed. Other treatment options like biologic agents should be considered in patients unresponsive to the maximum tolerable dose of colchicine to prevent amyloidosis. Although several definitions of colchicine resistant FMF exist in the literature, according to the most used one, colchicine resistance is defined as three or more attacks in 6 months or six or more attacks per year despite the appropriate drug compliance (44). In our daily practice, we have observed that some patients benefit from changing the brand of colchicine in the case of colchicine resistance, and this approach sometimes helps to get rid of the colchicine side effects like diarrhea. A recent study by Emmungil et al. (45) revealed that adult patients who are not responsive to domestic coated colchicine tablets could benefit from compressed colchicine preparations. Although not much evidence exists for this approach in children, it may be cost-effective and logical to try another brand of colchicine before using the biologic agents. In the case of colchicine resistant disease, anti-IL-1 agents like anakinra and canakinumab are recommended $(46,47)$.

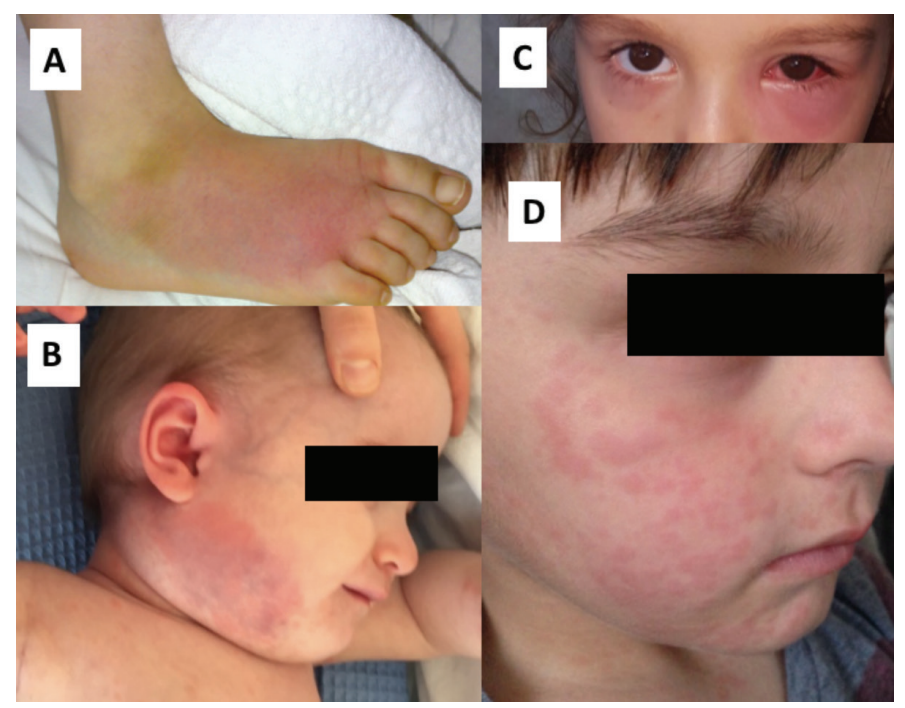

FIG. 2. A-D. Skin findings of the autoinflammatory diseases. A) Erysipelas-like erythema, B) cervical lymphadenopathy in patients with hyperimmunoglobulin D syndrome, C) periorbital edema, D) urticarial rash in patients with familial cold autoinflammatory syndrome.

\section{Hyperimmunoglobulin D syndrome or mevalonate kinase deficiency}

HIDS is an autosomal recessive autoinflammatory disease. It is caused by mutations in the $M V K$ gene that encodes mevalonate kinase, an enzyme that plays a crucial role in cholesterol biosynthesis (48). Of the approximately 100 described mutations of the $M V K$ gene, V377I has been reported to be the most common variant (49). MVK mutations lead to a decrease in the downstream product of the mevalonate kinase pathway, causing IL-1 $\beta$ secretion with resultant autoinflammation (50).

Disease severity highly correlates with the remaining enzymatic function (51). The $M V K$ enzyme activity in $M V K$-HIDS is reduced to $1 \%-8 \%$ of normal, whereas in mevalonic aciduria (MA), it is below $1 \%(52)$. MVK-HIDS is a milder condition, characterized by febrile episodes, combined with non-specific skin rashes, cervical lymphadenitis, arthritis or arthralgia, and severe gastrointestinal complaints, sometimes provoked by vaccination or infections (Figure 2B) (53). Episodes typically last 3-7 days and recur every 4-6 weeks (54). The frequency and severity of episodes decrease with age (55). Contrary to the nomenclature of the disease, $28 \%$ of patients do not have elevated immunoglobulin D levels (48). On the other hand, MA is more severe, characterized by episodes similar to those in mevalonate kinase deficiency-HIDS, but with a chronic disease course (56). In addition, mental retardation, dysmorphic features, and failure to thrive can be observed rarely in MA (57). According to recently proposed classification criteria, the presence of pathogenic (or likely pathogenic) $M V K$ variants (homozygous or in trans compound heterozygous) and at least one of the following symptoms are needed for diagnosis: gastrointestinal symptoms, cervical lymphadenitis, and aphthous stomatitis (22) (Table 4). The sensitivity and specificity of the new criteria were reported to be $98 \%$ and $100 \%$, respectively (22).

Corticosteroids have been shown to be effective in reducing symptoms, particularly during episodes (58). If steroids are unable to suppress the flares, treatment with a biological agent such as anti-IL-1 agents or anti-TNF agents should be considered $(59,60)$.

\section{Tumor necrosis factor receptor-associated periodic syndrome}

TRAPS is an autoinflammatory disease with periodic fever, musculoskeletal symptoms, skin changes, and eye findings (61). Although its exact prevalence is unknown, it is considered the most common autoinflammatory disease with an autosomal dominant inheritance pattern $(34,62)$.

The causative gene of the disease is TNF Receptor Super Family $1 A$ (TNFRSF1A) that is located on chromosome 12 (63-65). Most of the disease-related genes are located on exons 2, 3, and 4, and approximately 167 sequence variants have been identified thus far (https://infevers.umai-montpellier.fr/web/) (29). TNFRSF1A mutations are divided into the following two groups: structural and non-structural mutations. Structural mutations, especially in which cysteine bonds are affected, are reported to be associated with more severe disease and increased risk of amyloidosis (61-63,66). The most common mutations detected in patients with TRAPS are T50M and T50K related to hydrogen bonds (67). Mutations wherein the cysteine bonds are affected, such as C29S, C29Y, C29F, C29G, 
C29R, C30F, C30Y, C30S, C30R, C33G, and C33Y, and wherein the proline residues are affected, such as P46L, L67P, S86P, and R92P, are other significant examples of structural mutations $(61,62,67)$. Non-structural mutations, such as R92Q and P46L, are frequently noted in healthy individuals. Hence, their pathogenic significance is still controversial $(6,61,67)$. Patients with these mutations can develop clinical findings consistent with TRAPS but have a milder clinical course than patients with structural mutations $(6,47)$.

TRAPS can affect most organ systems and exhibit highly variable clinical findings. The most prominent finding of the disease is recurrent fever attacks that typically last 1-3 weeks and recur every 6 weeks (68). The disease duration is often longer than the other autoinflammatory diseases, and a persistent inflammatory course with intermittent flares is reported in some patients (34). Episodes of the disease typically start with muscle cramps or myalgia, followed by fever, skin rash, arthralgia, arthritis, and findings of the eye involvement. The most commonly reported skin rash is a migratory, centripetal, and erythematous rash (69). Rashes are typically observed on the muscle group exhibiting myalgia. Migratory myalgia is one of the most crucial clues for the disease and is reported to be detected in most patients (62). In addition, ocular findings like ocular pain, conjunctivitis, optic neuritis, and uveitis can be observed. Periorbital edema is pathognomonic for TRAPS, and should, therefore, be investigated in every patient with periodic fever $(61,62)$ (Figure 2C). Polyserositis is another well-defined finding of the disease and can be the only disease presentation
(70-72). Severe abdominal and thoracic pains could be present $(70,71)$. Furthermore, per the literature, recurrent pericarditis was reported as the only finding in some patients with TRAPS (72). In addition, non-erosive mono- or oligoarthritis, sacroiliitis, headache, scrotal pain, urethral stricture, and behavioral changes can be observed $(62,73,74)$.

Like the other autoinflammatory disease, the most significant complication of the disease is amyloidosis. Reportedly, the risk of amyloidosis increases, especially in the presence of structural mutations that affect cysteine residues (75).

Although various classification criteria for TRAPS have been proposed, the most recent one is the Eurofever/PRINTO criteria (22) (Table 5). The sensitivity and specificity of the new criteria were reported to be $95 \%$ and $99 \%$, respectively (22).

The primary aim of treatment is to urgently control the disease activity to resolve the illness, prevent treatment-related damages, and increase the quality of life of patients (47). Although nonsteroidal anti-inflammatory drugs (NSAIDs) have some symptomatic benefits in most patients, they often fail to cease the attacks (34). Steroids are generally successful in terminating attacks when used at a dose of $0.5-1 \mathrm{mg} / \mathrm{kg}$; however, in most patients, their efficacy decreases over time, and their long-term use is not recommended owing to their serious side effects $(34,47)$. Moreover, steroids are reported not to prevent amyloidosis, and often disease relapses after cessation (76). Ter Haar et al. (76) reported that patients with R92Q mutation respond better to NSAIDs and colchicine. In light of this information, it may be a logical strategy to try NSAIDs and steroids in patients with mild

TABLE 4. Eurofever/Pediatric Rheumatology International Trials Organization Hyperimmunoglobulin D Syndrome classification criteria (22)

\begin{tabular}{ll}
\hline Classification criteria & Clinical classification criteria \\
\hline Presence of pathogenic (or likely pathogenic) MVK variants (homozygous or in & Presence of at least three of the following six: \\
trans (or bi-allelic) compound heterozygous) and at least one of the following: & • Onset <1 year of age \\
- Gastrointestinal symptoms & - Gastrointestinal symptoms \\
- Cervical lymph nodes & $\bullet$ Painful lymphadenopathy \\
- Aphthous stomatitis & - Aphthous stomatitis \\
& - Triggers \\
& • Maculopapular rash \\
\hline
\end{tabular}

*Adapted from reference (22)

TABLE 5. Eurofever/Pediatric Rheumatology International Trials Organization tumor necrosis factor receptor-associated periodic syndrome classification criteria (22)

\begin{tabular}{|c|c|}
\hline Classification criteria & Clinical classification criteria \\
\hline $\begin{array}{l}\text { Presence of pathogenic (or likely pathogenic) TNFRSF1A variants (heterozygotes) and at least } \\
\text { one of the following: } \\
\text { - Duration of episodes } \geq 7 \text { days } \\
\text { - Myalgia } \\
\text { - Migratory rash } \\
\text { - Periorbital edema } \\
\text { - Relatives affected } \\
\text { OR } \\
\text { Presence of variant of uncertain significance of TNFRSF1A and at least two of the following: } \\
\text { - Duration of episodes } \geq 7 \text { days } \\
\text { - Myalgia } \\
\text { - Migratory rash } \\
\text { - Periorbital edema } \\
\text { - Relatives affected }\end{array}$ & $\begin{array}{l}\text { Score } \geq 5 \text { points: } \\
\text { Presence of } \\
\text { - Fever } \geq 7 \text { days ( } 2 \text { points }) \\
\text { - Fever } 5-6 \text { days ( } 1 \text { point }) \\
\text { - Migratory rash ( } 1 \text { point }) \\
\text { - Periorbital edema ( } 1 \text { point }) \\
\text { - Myalgia ( } 1 \text { point) } \\
\text { - Positive family history (1 point) } \\
\text { Absence of: } \\
\text { - Aphthous stomatitis ( } 1 \text { point }) \\
\text { - Pharyngotonsillitis ( } 1 \text { point })\end{array}$ \\
\hline
\end{tabular}


clinical findings, if needed, for a short period. Etanercept has been noted to be effective in preventing attacks and reducing steroid dose in some patients with TRAPS $(62,77)$. The efficacy of etanercept treatment decreases over time, and generally, another biological agent is needed in the process (76). Other anti-TNF agents, such as infliximab and adalimumab, have been noted to be ineffective and can paradoxically increase attacks (76). Another group of drugs used in the treatment of TRAPS is anti-IL-1 agents. Anakinra and canakinumab have been effective in both stopping and preventing attacks $(78,79)$.

\section{Cryopyrin associated periodic syndrome}

Cryopyrin associated periodic syndrome (CAPS) is an autoinflammatory disease with the following three distinct subtypes: familial cold autoinflammatory syndrome (FCAS), Muckle-Wells syndrome (MWS), and chronic infantile neurological, cutaneous, and articular (CINCA) or neonatalonset multisystem inflammatory disease (NOMID) (80). These three subtypes are considered the spectrum of a disease rather than separate entities. Some authors have suggested that the name of the disease should be changed to "NLRP3 associated autoinflammatory diseases," which reflects the responsible gene and covers all the three subtypes $(6,80)$.

Gain-of-function mutations in NLRP3 (CIAS1) gene encoding cryopyrin protein are responsible for CAPS (81).

All three subtypes of the disease reflect the different levels of disease severity and have both common and unique findings. Fever, flu-like symptoms, rashes, as well as ocular and central nervous system involvement can be observed in all three subtypes $(80,82)$. Disease episodes typically start with fever, fatigue, and flu-like nonspecific findings. Notably, the episodes typically end within a day in FCAS, whereas it can continue for three or more days in MWS and CINCA/NOMID. Furthermore, in CINCA/NOMID, a persistent inflammatory course with intermittent flares is reported in some patients (80). Skin rashes are often the first and prominent finding of the disease. Although urticaria is the most common skin finding, an erythematous rash, edematous papule, and plaque-like skin changes can be observed, too (Figure 2D). Histopathological evaluation of the urticaria-like rashes revealing the absence of mast cells helps in confirming these rashes as not real urticaria (83).

Musculoskeletal findings are another significant sign of the disease. Even though a pain in the extremities, myalgia, and arthralgia can be observed in all forms of the disease, arthritis is often seen in MWS and CINCA/NOMID and can be erosive in patients with CINCA/NOMID (82,84). Rarely, patients can develop bone deformities because of the uncontrolled growth of the patella, articular cartilage, or epiphysis of long bones, and this abnormal bone formation is unresponsive to anti-IL-1 treatment unlike other symptoms of the disease (82).

Progressive hearing loss is one of the main findings in patients with MWS and CINCA/NOMID but can be prevented and even partially regress with timely treatment $(34,82)$. Like the other symptoms of the disease, the severity of the ocular findings increases from FCAS to CINCA/NOMID. Uveitis, papilledema, and optic atrophy have been reported in CINCA/NOMID and rarely in MWS $(80,82,85,86)$.
Central nervous system involvement is a crucial cause of morbidity. Kilic et al. (87) reported that central nervous system involvement was detected in $50 \%$ of their patients with CAPS. The mildest form of central nervous system involvement is a headache, and it can be observed in all subtypes of the disease. Aseptic meningitis and increased intracranial pressure are among the common findings in patients with CINCA/NOMID (82). Notably, chronic leptomeningeal inflammation can cause adhesions and hydrocephalus (87). Developmental retardation, seizures, stroke, and vascular occlusions are the other central nervous system findings of the disease (82).

Thus far, 230 sequence variants have been identified in this gene (https://infevers.umai-montpellier.fr/web/) (29). Most of the disease-causing mutations are located in exon 3 of the gene. Figure 3 presents the mutations classified as pathogenic by Infevers database and the related phenotypes. Somatic mosaicism was reported in some patients with clinical findings consistent with CAPS, but none of the mutations were observed $(88,89)$. Therefore, it should be kept in mind that the absence of the NLRP3 gene mutation in patients with a strong suspicion of CAPS will not exclude the diagnosis, and patients should be evaluated regarding somatic mosaicism, if necessary.

The most recently proposed classification criteria for CAPS are the Eurofever/PRINTO criteria (22) (Table 6). In that study, researchers suggested two sets of criteria. Notably, one set consists of only clinical criteria that is a modified version of the classification criteria by Kuemmerle-Deschner et al. (90), whereas the other has genetic and clinical issues. The sensitivity and specificity of these criteria were both reported to be $100 \%$ (22).

Like in all the other autoinflammatory diseases, the primary purpose of treatment is to urgently control the disease activity, to resolve the illness, prevent treatment-related damages, and increase the quality of life of patients (47).

Because an increase in IL-1 cytokine level plays a crucial role in the pathogenesis of the disease, the appropriate treatment approach is to antagonize the effect of IL-1 $(47,80,82)$. Various studies have observed anakinra, canakinumab, and rilonacept to be effective in patients with CAPS (82,91-94).

In conclusion, the number of autoinflammatory diseases is increasing every day. Therefore, these diseases should be considered in

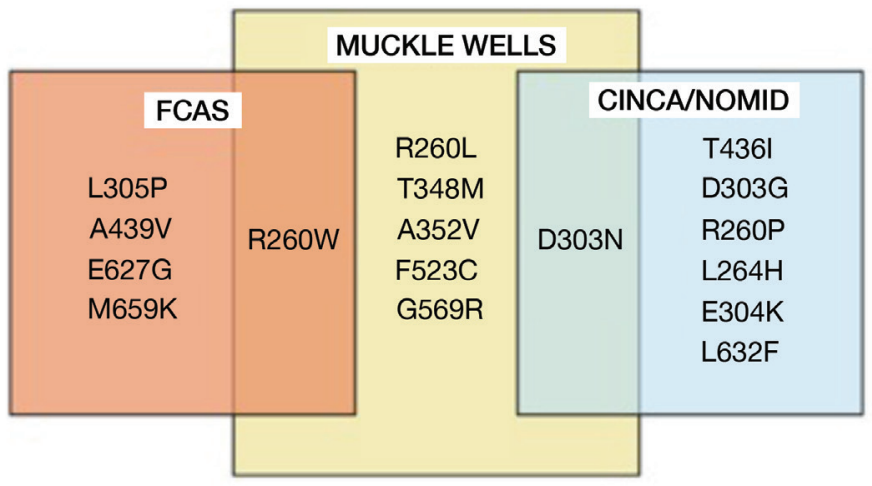

FIG. 3. Pathogenic NLRP3 gene variants according to Infevers database (29) and related phenotypes 
TABLE 6. Eurofever/Pediatric Rheumatology International Trials Organization classification criteria cryopyrin associated periodic syndrome (22)

\begin{tabular}{|c|c|}
\hline Classification criteria & Clinical classification criteria* \\
\hline Presence of pathogenic (or likely pathogenic) $N L R P 3$ variants (heterozygotes) and at & Presence of at least two of the following five: \\
\hline & • Urticarial rash \\
\hline - Urticarial rash & - Cold/stress triggered episodes \\
\hline - Neurosensorial hearing loss & - Chronic aseptic meningitis \\
\hline OR & - Skeletal abnormalities (epiphysial overgrowth/frontal bossing) \\
\hline Presence of variant of uncertain significance of $N L R P 3$ gene and at least two of the & Absence of: \\
\hline - Red eye (conjunctivitis, episcleritis, uveitis) & \\
\hline - Neurosensorial hearing loss & \\
\hline
\end{tabular}

the presence of skin and musculoskeletal system findings with accompanying periodic or recurrent fever during childhood. The diagnostic algorithm for suspected autoinflammatory diseases according to clinical findings is summarized in Figure 1. Despite the variable clinical findings of these diseases, the detection of pathogenic mutations strengthens the diagnostic and treatment approaches (95). Nevertheless, because most of these diseases are associated with the IL-1 pathway, anti-IL-1 treatment is the cornerstone in most of them.

Conflict of Interest: No conflict of interest was declared by the authors.

Financial Disclosure: No financial disclosure was declared by the authors.

\section{REFERENCES}

1. Ben-Chetrit E, Gattorno M, Gul A, Kastner DL, Lachmann HJ, Touitou I, et al. Consensus proposal for taxonomy and definition of the autoinflammatory diseases (AIDs): a Delphi study. Ann Rheum Dis 2018;77:1558-65.

2. McDermott MF, Aksentijevich I, Galon J, McDermott EM, Ogunkolade BW, Centola $\mathrm{M}$, et al. Germline mutations in the extracellular domains of the $55 \mathrm{kDa}$ TNF receptor, TNFR1, define a family of dominantly inherited autoinflammatory syndromes. Cell 1999;97:133-44.

3. Kastner DL, Aksentijevich I, Goldbach-Mansky R. Autoinflammatory disease reloaded: a clinical perspective. Cell 2010;140:784-90.

4. Wekell P, Berg S, Karlsson A, Fasth A. Toward an Inclusive, Congruent, and Precise Definition of Autoinflammatory Diseases. Front Immunol 2017;8:497.

5. Adrovic A, Sahin S, Barut K, Kasapcopur O. Familial Mediterranean fever and periodic fever, aphthous stomatitis, pharyngitis, and adenitis (PFAPA) syndrome: shared features and main differences. Rheumatol Int 2019;39:29-36.

6. Sag E, Bilginer Y, Ozen S. Autoinflammatory Diseases with Periodic Fevers. Curr Rheumatol Rep 2017;19:41.

7. Di Gioia SA, Bedoni N, von Scheven-Gete A, Vanoni F, Superti-Furga A, Hofer $\mathrm{M}$, et al. Analysis of the genetic basis of periodic fever with aphthous stomatitis, pharyngitis, and cervical adenitis (PFAPA) syndrome. Sci Rep 2015;5:10200.

8. Butbul Aviel Y, Harel L, Abu Rumi M, Brik R, Hezkelo N, Ohana O, et al. Familial Mediterranean Fever Is Commonly Diagnosed in Children in Israel with Periodic Fever Aphthous Stomatitis, Pharyngitis, and Adenitis Syndrome. J Pediatr 2019;204:270-4.

9. Manthiram K, Nesbitt E, Morgan T, Edwards KM. Family History in Periodic Fever, Aphthous Stomatitis, Pharyngitis, Adenitis (PFAPA) Syndrome. Pediatrics 2016;138:e20154572.

10. Vigo G, Martini G, Zoppi S, Vittadello F, Zulian F. Tonsillectomy efficacy in children with PFAPA syndrome is comparable to the standard medical treatment: a long-term observational study. Clin Exp Rheumatol 2014;32(4 Suppl 84):156-9.

11. Batu ED. Periodic fever, aphthous stomatitis, pharyngitis, and cervical adenitis (PFAPA) syndrome: main features and an algorithm for clinical practice. Rheumatol Int 2019;39:957-70.
12. Gattorno M, Caorsi R, Meini A, Cattalini M, Federici S, Zulian F, et al Differentiating PFAPA Syndrome From Monogenic Periodic Fevers. Pediatrics 2009;124:721-8.

13. Batu ED, Kara Eroğlu F, Tsoukas P, Hausmann JS, Bilginer Y, Kenna MA, et al. Periodic Fever, Aphthosis, Pharyngitis, and Adenitis Syndrome: Analysis of Patients From Two Geographic Areas. Arthritis Care Res (Hoboken) 2016;68:1859-65.

14. Gunes M, Cekic S, Kilic SS. Is colchicine more effective to prevent periodic fever, aphthous stomatitis, pharyngitis and cervical adenitis episodes in Mediterranean fever gene variants? Pediatr Int 2017;59:655-60.

15. Pehlivan E, Adrovic A, Sahin S, Barut K, Kul Cinar O, Kasapcopur O. PFAPA Syndrome in a Population with Endemic Familial Mediterranean Fever. J Pediatr 2018;192:253-5.

16. Perko D, Debeljak M, Toplak N, Avčin T. Clinical features and genetic background of the periodic Fever syndrome with aphthous stomatitis, pharyngitis, and adenitis: a single center longitudinal study of 81 patients. Mediators Inflamm 2015;2015:293417.

17. Berkun Y, Levy R, Hurwitz A, Meir-Harel M, Lidar M, Livneh A, et al. The familial Mediterranean fever gene as a modifier of periodic fever, aphthous stomatitis, pharyngitis, and adenopathy syndrome. Semin Arthritis Rheum 2011;40:467-72.

18. Taniuchi S, Nishikomori R, Iharada A, Tuji S, Heike T, Kaneko K. MEFV Variants in Patients with PFAPA Syndrome in Japan. Open Rheumatol J 2013;7:22-5.

19. Thomas KT, Feder HM Jr, Lawton AR, Edwards KM. Periodic fever syndrome in children. J Pediatr 1999;135:15-21.

20. Vanoni F, Caorsi R, Aeby S, Cochard M, Antón J, Berg S, et al. Towards a new set of classification criteria for PFAPA syndrome. Pediatr Rheumatol Online J 2018;16:60.

21. Adrovic A, Yıldız M, Kanber M, Ulkersoy I, Gucuyener N, Koker O, et al Performance of recently proposed periodic fever, aphthous stomatitis, pharyngitis, and cervical adenitis (PFAPA) syndrome criteria in a region endemic for familial Mediterranean fever. Rheumatol Int 2020;40:91-6.

22. Gattorno M, Hofer M, Federici S, Vanoni F, Bovis F, Aksentijevich I, et al. Classification criteria for autoinflammatory recurrent fevers. Ann Rheum Dis 2019;78:1025-32.

23. Vanoni F, Theodoropoulou K, Hofer M. PFAPA syndrome: a review on treatment and outcome. Pediatr Rheumatol Online J 2016;14:38.

24. Ozdogan H, Ugurlu S. Familial Mediterranean Fever. Presse Med 2019;48:61-76.

25. Ozen S, Bilginer Y. A clinical guide to autoinflammatory diseases: familial Mediterranean fever and next-of-kin. Nat Rev Rheumatol 2014;10:135-47.

26. Ben-Chetrit E, Touitou I. Familial Mediterranean Fever in the World. Arthritis Rheum 2009;61:1447-53.

27. French FMFC. A candidate gene for familial Mediterranean fever. Nat Genet 1997; 17:25-31.

28. Booth DR, Gillmore JD, Lachmann HJ, Booth SE, Bybee A, Soytürk M, et al. The genetic basis of autosomal dominant familial Mediterranean fever. QJM 2000;93:217-21.

29. Milhavet F, Cuisset L, Hoffman HM, Slim R, El-Shanti H, Aksentijevich I, et al. The infevers autoinflammatory mutation online registry: update with new genes and functions. Hum Mutat 2008;29:803-8. 
30. Ben-Zvi I, Herskovizh C, Kukuy O, Kassel Y, Grossman C, Livneh A. Familial Mediterranean fever without MEFV mutations: a case-control study. Orphanet J Rare Dis $2015 ; 10: 34$

31. Sohar E, Gafni J, Pras M, Heller H. Familial Mediterranean fever: A survey of 470 cases and review of the literature. Am J Med 1967;43:227-53.

32. Lidar M, Yaqubov M, Zaks N, Ben-Horin S, Langevitz P, Livneh A. The prodrome: a prominent yet overlooked pre-attack manifestation of familial Mediterranean fever. $\mathrm{J}$ Rheumatol 2006;33:1089-92.

33. Barut K, Sahin S, Adrovic A, Sinoplu AB, Yucel G, Pamuk G, et al. Familial Mediterranean fever in childhood: a single-center experience. Rheumatol Int 2018;38:67-74.

34. Lachmann HJ. Periodic fever syndromes. Best Pract Res Clin Rheumatol 2017;31:596609.

35. Ozer E, Seker D, Taner E, Adrovic A, Sahin S, Barut K, et al. The frequency of juvenile spondyloarthropathies in childhood familial Mediterranean fever. Clin Exp Rheumatol 2018;36(6 Suppl 115):141-5.

36. Kaplan E, Mukamel M, Barash J, Brik R, Padeh S, Berkun Y, et al. Protracted febrile myalgia in children and young adults with familial Mediterranean fever: analysis of 15 patients and suggested criteria for working diagnosis. Clin Exp Rheumatol 2007;25(4 Suppl 45):114-7.

37. Barut K, Guler M, Sezen M, Kasapçopur O. Inceased frequency of psoriasis in the families of the children with familial Mediterranean fever. Clin Exp Rheumatol 2016;34(6 Suppl 102):137.

38. Yildiz M, Adrovic A, Tasdemir E, Baba-Zada K, Aydin M, Koker O, et al. Evaluation of co-existing diseases in children with familial Mediterranean fever. Rheumatol Int 2020;40:57-64.

39. Yalçinkaya F, Ozen S, Ozçakar ZB, Aktay N, Cakar N, Düzova A, et al. A new set of criteria for the diagnosis of familial Mediterranean fever in childhood. Rheumatology (Oxford) 2009;48:395-8.

40. Livneh A, Langevitz P, Zemer D, Zaks N, Kees S, Lidar T, et al. Criteria for the diagnosis of familial Mediterranean fever. Arthritis Rheum 1997;40:1879-85.

41. Sag E, Demirel D, Demir S, Atalay E, Akca U, Bilginer Y, et al. Performance of the new 'Eurofever/PRINTO classification criteria' in FMF patients. Semin Arthritis Rheum 2020;50:172-5.

42. Ozkan E, Okur O, Ekmekci A, Ozcan R, Tag T. A new approach to the treatment of periodic fever. Med Bull Istanbul. 1972;5:44-9.

43. Goldfinger SE. Colchicine for familial Mediterranean fever. N Engl J Med 1972;287:1302.

44. Hentgen V, Grateau G, Kone-Paut I, Livneh A, Padeh S, Rozenbaum M, et al. Evidence-based recommendations for the practical management of Familial Mediterranean Fever. Semin Arthritis Rheum 2013;43:387-91.

45. Emmungil H, İlgen U, Turan S, Yaman S, Küçükşahin O. Different pharmaceutical preparations of colchicine for Familial Mediterranean Fever: are they the same? Rheumatol Int 2020;40:129-35

46. De Benedetti F, Gattorno M, Anton J, Ben-Chetrit E, Frenkel J, Hoffman HM, et al. Canakinumab for the Treatment of Autoinflammatory Recurrent Fever Syndromes. N Engl J Med 2018;378:1908-19.

47. Ter Haar NM, Oswald M, Jeyaratnam J, Anton J, Barron KS, Brogan PA, et al. Recommendations for the management of autoinflammatory diseases. Ann Rheum Dis 2015;74:1636-44.

48. Ammouri W, Cuisset L, Rouaghe S, Rolland M-O, Delpech M, Grateau G, et al. Diagnostic value of serum immunoglobulinaemia $\mathrm{D}$ level in patients with a clinical suspicion of hyper IgD syndrome. Rheumatology (Oxford) 2007;46:1597-600.

49. Pepper RJ, Lachmann HJ. Autoinflammatory syndromes in children. Indian J Pediatr 2016;83:242-7.

50. Drenth JP, Cuisset L, Grateau G, Vasseur C, van de Velde-Visser SD, de Jong JG, et al. Mutations in the gene encoding mevalonate kinase cause hyper-IgD and periodic fever syndrome. Nat Genet 1999;22:178-81.

51. Simon A, van der Meer JW. Pathogenesis of familial periodic fever syndromes or hereditary autoinflammatory syndromes. Am J Physiol Regul Integr Comp Physiol 2007;292:86-98.

52. Dueckers G, Sander O, Niehues T. Autoinflammatory diseases (AID). Klin Pädiatr 2014;226:133-42.

53. Rigante D, Frediani B, Cantarini L. A comprehensive overview of the hereditary periodic fever syndromes. Clin Rev Allergy Immunol 2018;54:446-53.
54. Tripathi SV, Leslie KS. Autoinflammatory Diseases in Dermatology: CAPS, TRAPS, HIDS, FMF, Blau, CANDLE. Dermatol Clin 2013;31:387-404.

55. Drenth JP, Van Der Meer JW. Hereditary periodic fever. N Engl J Med 2001;345:1748-57

56. Havnaer A, Han G. Autoinflammatory disorders: a review and update on pathogenesis and treatment. Am J Clin Dermatol 2019;20:539-64.

57. Hoffmann GF, Charpentier C, Mayatepek E, Mancini J, Leichsenring M, Gibson KM, et al. Clinical and biochemical phenotype in 11 patients with mevalonic aciduria. Pediatrics 1993;91:915-21.

58. van der Hilst JC, Bodar EJ, Barron KS, Frenkel J, Drenth JP, van der Meer JW, et al Long-term follow-up, clinical features, and quality of life in a series of 103 patients with hyperimmunoglobulinemia D syndrome. Medicine (Baltimore) 2008;87:301-10.

59. Rigante D, Ansuini V, Bertoni B, Pugliese AL, Avallone L, Federico G, et al Treatment with anakinra in the hyperimmunoglobulinemia $\mathrm{D} /$ periodic fever syndrome. Rheumatol Int 2006;27:97-100.

60. Takada K, Aksentijevich I, Mahadevan V, Dean JA, Kelley RI, Kastner DL. Favorable preliminary experience with etanercept in two patients with the hyperimmunoglobulinemia D and periodic fever syndrome. Arthritis Rheum 2003;48:2645-51.

61. Cantarini L, Lucherini OM, Muscari I, Frediani B, Galeazzi M, Brizi MG, et al. Tumour necrosis factor receptor-associated periodic syndrome (TRAPS): state of the art and future perspectives. Autoimmun Rev 2012;12:38-43.

62. Rigante D, Lopalco G, Vitale A, Lucherini OM, De Clemente C, Caso F, et al. Key facts and hot spots on tumor necrosis factor receptor-associated periodic syndrome. Clin Rheumatol 2014;33:1197-207.

63. Aksentijevich I, Galon J, Soares M, Mansfield E, Hull K, Oh HH, et al. The tumornecrosis-factor receptor-associated periodic syndrome: new mutations in TNFRSF1A, ancestral origins, genotype-phenotype studies, and evidence for further genetic heterogeneity of periodic fevers. Am J Hum Gen 2001;69:301-14.

64. Mulley J, Saar K, Hewitt G, Rüschendorf F, Phillips H, Colley A, et al. Gene localization for an autosomal dominant familial periodic fever to $12 \mathrm{p} 13$. Am J Hum Gene 1998;62:884-9.

65. McDermott MF, Ogunkolade BW, McDermott EM, Jones LC, Wan Y, Quane KA, et al. Linkage of familial Hibernian fever to chromosome 12p13. American J Hum Genet 1998;62:1446-51.

66. Ravet N, Rouaghe S, Dodé C, Bienvenu J, Stirnemann J, Lévy P, et al. Clinical significance of $\mathrm{P} 46 \mathrm{~L}$ and $\mathrm{R} 92 \mathrm{Q}$ substitutions in the tumour necrosis factor superfamily 1A gene. Ann Rheum Dis 2006;65:1158-62.

67. Aksentijevich I, Kastner DL. Genetics of monogenic autoinflammatory diseases: past successes, future challenges. Nat Rev Rheumatol 2011;7:469-78.

68. Stojanov S, McDermott MF. The tumour necrosis factor receptor-associated periodic syndrome: current concepts. Expert Rev Mol Med 2005;7:1-18.

69. Toro JR, Aksentijevich I, Hull K, Dean J, Kastner DL. Tumor necrosis factor receptorassociated periodic syndrome: a novel syndrome with cutaneous manifestations. Arch Dermatol 2000;136:1487-94.

70. Cantarini L, Lucherini OM, Cimaz R, Brizi MG, Galeazzi M. Serosal involvement in adult-onset autoinflammatory disorders. Respiration 2010;80:260-2.

71. Cantarini L, Lucherini OM, Cimaz R, Galeazzi M. Recurrent pericarditis caused by a rare mutation in the TNFRSF1A gene and with excellent response to anakinra treatment. Clin Exp Rheumatol 2010;28:802.

72. Dodé C, André M, Bienvenu T, Hausfater P, Pêcheux C, Bienvenu J, et al. The enlarging clinical, genetic, and population spectrum of tumor necrosis factor receptorassociated periodic syndrome. Arthritis Rheum 2002;46:2181-8.

73. Cantarini L, Lucherini OM, Cimaz R, Baldari CT, Laghi Pasini F, Galeazzi M. Sacroileitis and pericarditis: atypical presentation of tumor necrosis factor receptorassociated periodic syndrome and response to etanercept therapy. Clin Exp Rheumatol 2010;28:290-1.

74. Trost S, Rosé CD. Myocarditis and sacroiliitis: 2 previously unrecognized manifestations of tumor necrosis factor receptor associated periodic syndrome. J Rheumatol 2005;32:175-7.

75. Obici L, Merlini G. Amyloidosis in autoinflammatory syndromes. Autoimmunity Rev 2012;12:14-7.

76. Ter Haar N, Lachmann H, Özen S, Woo P, Uziel Y, Modesto C, et al. Treatment of autoinflammatory diseases: results from the Eurofever Registry and a literature review. Ann Rheum Dis 2013;72:678-85.

77. Cantarini L, Lucherini OM, Galeazzi M, Fanti F, Simonini G, Baldari CT, et al Tumour necrosis factor receptor-associated periodic syndrome caused by a rare 
mutation in the TNFRSF1A gene, and with excellent response to etanercept treatment. Clin Exp Rheumatol 2009;27:890-1.

78. Gattorno M, Pelagatti MA, Meini A, Obici L, Barcellona R, Federici S, et al. Persistent efficacy of anakinra in patients with tumor necrosis factor receptor-associated periodic syndrome. Arthritis Rheum 2008;58:1516-20.

79. De Benedetti F, Gattorno M, Anton J, Ben-Chetrit E, Frenkel J, Hoffman HM, et al Canakinumab for the Treatment of Autoinflammatory Recurrent Fever Syndromes. N Engl J Med 2018;378:1908-19.

80. Booshehri LM, Hoffman HM. CAPS and NLRP3. J Clin Immunol 2019;39:277-86

81. Aksentijevich I, Putnam CD, Remmers EF, Mueller JL, Le J, Kolodner RD, et al. The clinical continuum of cryopyrinopathies: novel CIAS1 mutations in North American patients and a new cryopyrin model. Arthritis Rheum 2007;56:1273-85.

82. Kuemmerle-Deschner JB. CAPS--pathogenesis, presentation and treatment of an autoinflammatory disease. Semin Immunopathol 2015;37:377-85.

83. Kastner DL. Hereditary periodic fever syndromes. Hematology Am Soc Hematol Educ Program 2005:74-81.

84. Hoffman HM, Mueller JL, Broide DH, Wanderer AA, Kolodner RD. Mutation of a new gene encoding a putative pyrin-like protein causes familial cold autoinflammatory syndrome and Muckle-Wells syndrome. Nat Genet 2001;29:301-5.

85. Dollfus H, Häfner R, Hofmann HM, Russo RA, Denda L, Gonzales LD, et al Chronic infantile neurological cutaneous and articular/neonatal onset multisystem inflammatory disease syndrome: ocular manifestations in a recently recognized chronic inflammatory disease of childhood. Arch Ophthalmol 2000;118:1386-92.

86. Alejandre N, Ruiz-Palacios A, García-Aparicio AM, Blanco-Kelly F, Bermúdez S, Fernández-Sanz G, et al. Description of a new family with cryopyrin-associated periodic syndrome: risk of visual loss in patients bearing the R260W mutation. Rheumatology (Oxford) 2014;53:1095-9.

87. Kilic H, Sahin S, Duman C, Adrovic A, Barut K, Turanli ET, et al. Spectrum of the neurologic manifestations in childhood-onset cryopyrin-associated periodic syndrome. Eur J Paediat Neurol 2019;23:466-72.
88. Tanaka N, Izawa K, Saito MK, Sakuma M, Oshima K, Ohara O, et al. High incidence of NLRP3 somatic mosaicism in patients with chronic infantile neurologic, cutaneous, articular syndrome: Results of an international multicenter collaborative study. Arthritis Rheum 2011;63:3625-32.

89. Eroglu FK, Kasapcopur O, Beşbaş N, Ozaltin F, Bilginer Y, Barut K, et al. Genetic and clinical features of cryopyrin-associated periodic syndromes in Turkish children. Clin Exp Rheumatol 2016;34(6 Suppl 102):115-20.

90. Kuemmerle-Deschner JB, Ozen S, Tyrrell PN, Kone-Paut I, Goldbach-Mansky R, Lachmann H, et al. Diagnostic criteria for cryopyrin-associated periodic syndrome (CAPS). Ann Rheum Dis 2017:76:942-7.

91. Leslie KS, Lachmann HJ, Bruning E, McGrath JA, Bybee A, Gallimore JR, et al. Phenotype, genotype, and sustained response to anakinra in 22 patients with autoinflammatory disease associated with CIAS-1/NALP3 mutations. Arch Dermatol 2006;142:1591-7

92. Ross JB, Finlayson LA, Klotz PJ, Langley RG, Gaudet R, Thompson K, et al. Use of anakinra (Kineret) in the treatment of familial cold autoinflammatory syndrome with a 16-month follow-up. J Cutan Med Surg 2008;12:8-16.

93. Hoffman HM, Throne ML, Amar NJ, Sebai M, Kivitz AJ, Kavanaugh A, et al. Efficacy and safety of rilonacept (interleukin-1 Trap) in patients with cryopyrin-associated periodic syndromes: results from two sequential placebo-controlled studies. Arthritis Rheum 2008;58:2443-52

94. Lachmann HJ, Kone-Paut I, Kuemmerle-Deschner JB, Leslie KS, Hachulla E, Quartier P, et al. Use of canakinumab in the cryopyrin-associated periodic syndrome. N Engl J Med 2009;360:2416-25.

95. Karacan İ, Balamir A, Uğurlu S, Aydın AK, Everest E, Zor S, et al. Diagnostic utility of a targeted next-generation sequencing gene panel in the clinical suspicion of systemic autoinflammatory diseases: a multi-center study. Rheumatology Int 2019;39:911-9. 